\title{
Tryptase and IgE concentrations in the respiratory tract of infants with acute bronchiolitis
}

\author{
Mark L Everard, Grenville Fox, Andrew F Walls, Diana Quint, Richard Fifield, \\ Carol Walters, Andrea Swarbrick, Anthony D Milner
}

\begin{abstract}
It has been proposed that a specific IgE response contributes to the immunopathology of acute respiratory syncytial virus (RSV) bronchiolitis but previous work has been difficult to replicate. Indirect evidence that might support this contention was sought by measuring total IgE concentrations in bronchoalveolar lavage (BAL) samples obtained from intubated infants and by attempting to detect mRNA for IgE in cells obtained from both the upper and lower respiratory tract. Evidence of significant mast cell activation was sought by measuring tryptase concentrations in BAL fluid and serum.
\end{abstract}

Detectable concentrations of IgE were found in two of seven BAL samples obtained more than five days after intubation and mRNA for IgE was demonstrated in three of six BAL samples and three of six samples obtained from the upper respiratory tract. Tryptase was detectable in 11 of 12 BAL samples with the two highest values detected on day 1 . These values were raised compared with control samples but were not such to suggest that mast cell degranulation is the major contributor to the inflammatory process.

These results suggest that IgE may be produced in the airways of infants in response to $\mathrm{RSV}$ infection. The relationships between IgE production, $R S V$ infection, and symptoms of acute bronchiolitis remain obscure.

(Arch Dis Child 1995; 72: 64-69)

Keywords: acute bronchiolitis, bronchoalveolar lavage, IgE, tryptase.

Super-regional Protein Reference Laboratory, Cardiff Royal

Infirmary

R Fifield

Department of Paediatrics,

St Thomas's Hospital,

London

G Fox

A D Milner

Correspondence to: Dr Mark Everard, Department of Paediatrics, Gloucestershire Royal Hospital, Great Western Road, Gloucester GL1 3NN. Accepted 19 September 1994 a distinctive disease while most who become infected simply develop upper respiratory tract symptoms. ${ }^{3}$ One of the earliest theories proposed that acute bronchiolitis may result
Respiratory syncytial virus (RSV) is responsiand remains a major cause of morbidi have been pursuing a variety of possible immunopathological mechanisms that might from a type I hypersensitivity reaction involving $\operatorname{IgE}, 4$ and that the infants had previously encountered the virus earlier in the winter epidemic and developed acute bronchiolitis when subsequently re-exposed to the virus. Subsequent epidemiological studies argued convincingly that prior exposure was most unlikely in that the age distribution of the illness did not change as the epidemic progressed, and the curves representing the incidence of upper respiratory tract illness and that of bronchiolitis are essentially parallel. ${ }^{5}$ Further it was well recognised that these infants do not demonstrate an accelerated secondary antibody response to the virus during the acute illness and indeed those affected usually have delayed or absent response.

The possibility that IgE might be involved in the genesis of the disease was again raised more than a decade ago by a group who produced results suggesting that some infants infected by the virus produce a RSV specific antibody response detectable in nasal secretions. ${ }^{6-10}$ Their studies have shown that this response appears to be detected more commonly in those with lower respiratory tract disease while peak concentrations tend to correlate with both severity of the acute illness, as determined by the degree of hypoxia, ${ }^{7}$ and the prevalence of subsequent symptoms. ${ }^{9}$ The magnitude of this response does not appear to be age related. Unfortunately these results have proved very difficult to reproduce, ${ }^{11}$ although one study has produced similar results correlating serum RSV IgE and $\mathrm{IgG}_{4}$ concentrations with the likelihood of wheeze. ${ }^{12}$

There have been several studies showing that atopy is not an important predisposing factor for developing acute bronchiolitis, ${ }^{13-15}$ and that serum IgE is not increased in an epidemic of bronchiolitis. ${ }^{16}$ Therefore it would appear that these infants are not genetically predisposed to producing increased IgE concentrations. Hence, if a mucosal IgE response is induced by the virus, this must be due to the virus's ability to modulate the host immune response in some way.

It is important to determine whether a predominant IgE response does occur in these infants for a number of reasons. Previous attempts to produce a vaccine have been either unsuccessful, ${ }^{17}$ or have resulted in abnormally 
severe disease in infants after natural infection by the virus. ${ }^{18}$ Hence clarification of the immunological mechanisms involved in the host-virus interaction in infants with RSV bronchiolitis may be essential if a safe and effective vaccine is to be produced. Furthermore, any antibody response will be a primary response as these infants have not previously encountered the virus. It is therefore possible that if an RSV specific IgE response is occurring in these infants then this might be the one situation in which this response can be studied in humans.

In this study we sought to obtain indirect evidence for an IgE response by measuring total IgE concentrations in bronchial lavage samples and using a polymerase chain reaction (PCR) method to identify mRNA for $\operatorname{IgE}$ in cells obtained from the upper and lower respiratory tract. Tryptase, a mast cell specific mediator, was also measured in bronchial lavage fluid and serum.

\section{Patients and methods}

PATIENTS

All patients enrolled in the study were previously healthy infants who were admitted with a diagnosis of RSV bronchiolitis confirmed by indirect immunofluorescence on nasopharyngeal aspirates. All were under 6 months of age at the time of admission. Bronchoalveolar lavage (BAL) samples were obtained from a total of 12 patients intubated for RSV bronchiolitis. Total IgE or tryptase concentrations were measured in the resulting supernatant, while cells obtained from the upper and lower respiratory tract were processed in order that mRNA could be identified. Because of the small volume of fluid recovered after BAL, the resulting supernatant from each sample was used only in one aspect of the study. Twenty one nasopharyngeal samples were used from these patients for mRNA analysis and serum samples were obtained from intubated and non-intubated patients for measurement of tryptase. Ethics committee approval was obtained for this study and informed consent obtained from parents.

Total IgE and albumin concentrations were measured in eight BAL samples obtained from six patients during the first winter's epidemic. Six of these samples were obtained within 48 hours of intubation; two repeat samples were obtained more than 120 hours after intubation. Supernatant from 13 samples obtained from six patients during the second winter were concentrated using Amicon 10 microconcentrators in which the final volume was reduced to approximately $200 \mu \mathrm{l}$. This represented an increase in concentration of between five and 10 -fold. Five of these samples were taken more than 120 hours after intubation.

RNA was extracted from cells obtained from the upper and lower respiratory tract of infants intubated for RSV bronchiolitis. A PCR method was used to detect message for IgE, $T$ cell receptor, and actin in 12 randomly selected samples from a total of $21 \mathrm{BAL}$ and 21 nasopharyngeal samples obtained at varying time intervals after intubation. Six of these samples were obtained from BAL and six from nasopharyngeal aspirates. In four samples in which mRNA for T cell receptor was detected, evidence of mRNA for interleukin-4 and interferon gamma synthesis was also sought.

Tryptase values were assayed in $12 \mathrm{BAL}$ samples obtained from four patients. Samples were obtained within 24 hours of admission and at least one repeat sample was obtained from each patient during the next four days. A further 11 bronchial lavage samples were obtained from 10 patients intubated for non-respiratory conditions and these were used as controls. These patients had had cardiac surgery (eight), abdominal surgery (one), and surgery for burns (one). These were obtained as soon after intubation as possible with one repeat sample being obtained four days after intubation.

For analysis of serum tryptase, 11 samples from 11 non-ventilated patients and 20 samples from 14 ventilated patients were obtained as soon after admission or intubation as possible and repeat samples were obtained between one and three days later in four ventilated subjects. Control samples were collected from 15 healthy infants (aged from 1-5 months), blood being obtained from a cannula inserted preoperatively in healthy infants undergoing routine repair of inguinal hernia. The children were anaesthetised with gaseous agents at the time the cannulas were inserted.

\section{COLLECTION OF SAMPLES}

Nasopharyngeal aspirates were obtained using a standard technique with a catheter being introduced into the nasopharynx through the nose and $8 \mathrm{kPa}$ of suction being applied as the catheter was withdrawn.

Bronchial lavage was performed at the time of routine endotracheal suction using a technique based on one previously described for obtaining lavage samples from preterm infants with chronic lung disease ${ }^{19}$ Infants were oxygenated for two minutes before the procedure. A suction catheter was passed through the endotracheal tube with the infants head turned to the left. This was designed to introduce the suction catheter into the right main bronchus. Normal saline at $1 \mathrm{ml} / \mathrm{kg}$ was warmed to $37^{\circ} \mathrm{C}$ and introduced through the catheter in to the right main bronchus and after a five second delay aspirated using $8 \mathrm{kPa}$ of suction. The aspirate was collected into a trap that was placed on ice until processed.

\section{PROCESSING OF SAMPLES}

The tracheal aspirates and nasopharyngeal aspirates were placed in a centrifuge tube and agitated with a pipette to break up mucus in the sample. Larger aggregates of mucus were removed with a pipette and the lavage fluid was allowed to stand. Fine debris was removed from the surface with a pipette and the remaining fluid removed leaving heavy debris at the base of the tube. The samples were placed in a second tube and centrifuged at $300 \mathrm{~g}$ for five 
minutes, the supernatant then being removed and frozen at $-70^{\circ} \mathrm{C}$ to be analysed subsequently. The pellet of cells was then resuspended in normal saline.

\section{TOTAL IgE AND ALBUMIN ASSAY}

Total IgE concentrations in bronchial lavage were assayed using the Pharmacia CAP system that utilises a double antibody sandwich technique. Standards used in this assay were calibrated against the first IRP 75/502. Albumin was assayed using a rate nephelometry technique using a Beckman Array immunochemistry analyser. Standards used in this assay are calibrated against IFCC 74/1.

\section{ISOLATION AND ANALYSIS RNA}

A technique based on that described by Gough $^{20}$ was used where cells were placed in a $1.5 \mathrm{ml}$ Eppendorf tube to which $2 \mu \mathrm{l}$ of RNA guard (Pharmacia) were added and the cells were resuspended in $200 \mu \mathrm{l}$ of ice cold solution 1 (10 mM Tris-hydrochloric acid, $\mathrm{pH} 7 \cdot 5,0 \cdot 1 \mathrm{M}$ sodium chloride, $1.5 \mathrm{mM}$ magnesium chloride, and $0.65 \%$ NP-40). The cells were then vortexed and centrifuged at $6500 \mathrm{rpm}$ for five minutes to pellet the nuclei. Supernatant was transferred to a fresh tube containing $200 \mu \mathrm{l}$ of solution 2 ( $7 \mathrm{M}$ urea, $1 \%$ SDS, $0.35 \mathrm{M}$ sodium chloride, 10 mM EDTA, $10 \mathrm{mM}$ Tris-hydrochloride acid, $\mathrm{pH} 7 \cdot 5)$ and $400 \mu \mathrm{l}$ of a phenol/chloroform mixture (phenol/chloroform/isoamyl alcohol (50:50:1) saturated with TE buffer $(100 \mathrm{mM}$ Tris, $50 \mathrm{mM}$ EDTA, pH 7.5)) and vortexed vigorously. This was centrifuged at 13000 rpm for three minutes and the supernatant removed to a fresh tube. Two volumes of $100 \%$ ethanol and $0 \cdot 1$ volume of three molar sodium acetate were added and the cells left to precipitate at $-20^{\circ} \mathrm{C}$ overnight. These were spun in the microcentrifuge at $13000 \mathrm{rpm}$ for 15 minutes. The ethanol was removed by decanting and the dry pellet was resuspended in $20 \mu \mathrm{l}$ of diethylpyrocarbonate treated sterile water. The RNA was then stored at $-20^{\circ} \mathrm{C}$.

Analysis was carried out using a previously described PCR method. ${ }^{21}$ cDNA was synthesised from total RNA as template using an oligo-dT primer $(n=18)$ and avian myeloblastosis virus reverse transcriptase (Promega). For the PCR $5 \mu$ l aliquots of the resulting 200 $\mathrm{ml}$ cDNA were amplified in a $50 \mu \mathrm{l}$ reaction volume containing $200 \mu \mathrm{M}$ dNTP mix, $5 \mu l 10$ fold PCR buffer and 1 unit Taq DNA polymerase (both from Promega) during 30 cycles $\left(1 \mathrm{~min}\right.$ denaturation at $92^{\circ} \mathrm{C}, 1 \mathrm{~min}$ anneal at $500^{\circ} \mathrm{C}$, and $2 \mathrm{~min}$ extension at $72^{\circ} \mathrm{C}$ ). An aliquot of $10 \mu \mathrm{l}$ of the reaction product was analysed on a $2 \%$ agarose gel in Tris borateEDTA buffer containing $0.5 \mu \mathrm{g} / \mathrm{ml}$ ethidium bromide. In all experiments control PCR without CDNA were performed to exclude contamination; PCR primers were designed to yield products crossing introns to allow genomic DNA and cDNA products to be distinguished. Primers used in these studies, synthesised on the Applied Biosystems DNA synthesiser were as follows: actin sense: $5^{\prime}$ CTGGCACCCAGCACAA TGAAG 3', Antisense: 5' ACCGACTGCTGTCACCTTCA 3', T cell receptor sense: 5' TTC TACGGGCTCTCGGAGAATGACG $3^{\prime}$, antisense: $\quad 5^{\prime}$ GCAGGATCTCATAGAG GATGGTGGC $3^{\prime}$ interleukin-4 sense: 5' CTGCAAATCGACACCTATTA 3', antisense: 5' GATCGTCT TTAGCCTTTC $3^{\prime}$, interferon gamma sense: 5' GGTCATTCAGATGTAGCGGA 3', antisense: 5' GCTTGG ACATTCAAGTCAG 3', and IgE sense: 5' CGACAACAA AACCTTCAGCG 3', antisense: 5' AC CCTCCTGCGTGGTAGAGG 3'.

\section{ANALYSIS OF TRYPTASE VALUES IN BAL AND} SERUM

Concentrations of mast cell tryptase in BAL fluid were measured using a radioimmunoassay with tryptase specific monoclonal antibody $\mathrm{AA} 5^{22}$ coupled to cyanogen bromide activated agarose (Pharmacia). Duplicate samples $(100 \mu \mathrm{l})$ of BAL fluid concentrated 10 times by freeze drying, or tryptase standards ( 2 to $50 \mathrm{ng} / \mathrm{ml}$ in $100 \mu \mathrm{l}$, Pharmacia) were incubated with AA5-agarose $(25 \mathrm{mg}$ in 100 $\mu \mathrm{l}$ ), shaking continuously (16 hours at room temperature). After washing with Tris buffer (pH 7.6), $25 \mu l$ of ${ }^{125}$ I antitryptase monoclonal antibody (Pharmacia) was added and incubated for 16 hours. The tubes were washed with $0.9 \%$ saline and counted in a gamma counter. The method had an effective lower limit of sensitivity of $0.1 \mathrm{ng} / \mathrm{ml}$ when allowing for the concentration step.

\section{STATISTICAL ANALYSIS}

Data from serum samples were analysed using a one way analysis of variance. Significant differences between means were assessed using a Fisher protected least significant difference test. Concentrations in BAL fluid were compared using the Mann-Whitney non-parametric test.

\section{Results}

TOTAL IgE AND ALBUMIN CONCENTRATIONS

During the first winter epidemic none of the eight samples obtained within the first five days after intubation contained IgE detectable by the above method. However, in two samples obtained at six and eight days respectively, measurable concentrations of IgE were obtained from the supernatant. The concentration of IgE in these two lavage samples were IgE $2 \mathrm{IU} / 1$ and $4 \mathrm{IU} / 1$ while IgE/albumin ratios were 0.090 and $0.014 \mathrm{IU} / \mathrm{mg}$. Earlier samples obtained from both these subjects did not contain measurable concentrations of IgE. Albumin concentrations were relatively high in all samples ranging from 22 to $625 \mathrm{mg} / 1$ (median 127.5).

During the second winter epidemic, despite concentrating the samples, no IgE was detected in any early or late samples obtained by bronchial lavage. 


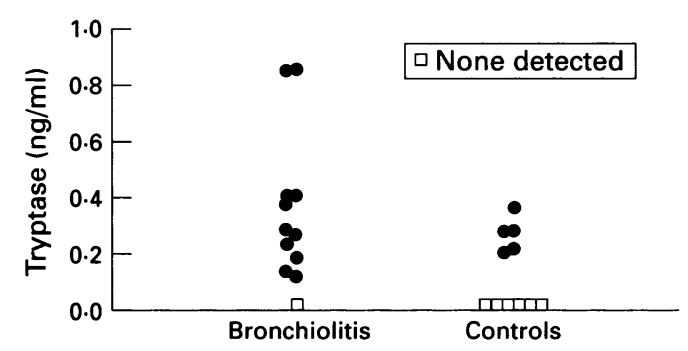

Tryptase concentrations in BAL samples obtained from infants with RSV bronchiolitis and from control infants intubated for non-respiratory indications. Lower level of detection $0 \cdot 1 \mathrm{ng} / \mathrm{ml}$.

MRNA

Messenger RNA for IgE was detected in three of six bronchial lavage samples and three of six nasopharyngeal samples. No mRNA for interleukin-4, interleukin-5, or interferon gamma was detected in the two lavage and two nasopharyngeal samples examined for these cytokines despite detectable mRNA for $T$ cell receptor in these samples.

\section{TRYPTASE}

The concentrations of tryptase contained in the serum of patients with RSV bronchiolitis were found to be significantly lower in samples from both intubated and non-intubated patients with RSV bronchiolitis than in controls $(p<0.01)$. For controls, concentrations fell in the range $2 \cdot 2-13 \cdot 1 \mathrm{ng} / \mathrm{ml}$ (median $7 \cdot 4$ ) compared with $<2 \cdot 0-8 \cdot 1 \mathrm{ng} / \mathrm{ml}$ (median $3 \cdot 9$ ) in non-ventilated patients with bronchiolitis and $<2-7.4 \mathrm{ng} / \mathrm{ml}$ (median 4.6 ) in seven samples from four ventilated patients. There was no significant difference between serum tryptase values in samples from non-ventilated and ventilated patients.

The tryptase concentrations in BAL supernatants from the RSV bronchiolitis patients were significantly greater than in control samples $(p<0.03)$. Tryptase in BAL fluid obtained from control patients was undetectable in six of 11 samples and in the range 0.21 to $0.37 \mathrm{ng} / \mathrm{ml}$ in the other five samples. In patients with bronchiolitis, concentrations were in the range undetectable (one of 12 samples) to $0.86 \mathrm{ng} / \mathrm{ml}$ (median $0.28 \mathrm{ng} / \mathrm{l}$ ) (see figure).

\section{Discussion}

This study used a number of novel approaches in an attempt to unravel some of the mysteries of the host-virus response in acute RSV bronchiolitis. The study addressed aspects of the inflammatory process both in the upper and lower respiratory tract and specifically addressed the contention that an IgE response occurs during the primary exposure to the virus and that this in some way contributes to the acute illness. The study has shown that techniques such as PCR can be applied to the study of this condition and though not definitive, these results suggest that valuable information can be gained by using modern molecular techniques to study this disease in the human host.
We chose to study samples from the respiratory tract in an attempt to determine whether an IgE response does occur as there is good evidence that significant local production of IgE occurs within the respiratory tract, ${ }^{23} 24$ and it is probable that circulating concentrations of IgE do not reflect events at the epithelial surface. One study from Welliver et al has suggested that this is the case for the RSV specific IgE response. ${ }^{8}$ Samples from both the upper and lower respiratory tract were studied as it is unclear from previous studies whether results obtained from using nasal samples are representative of events in the lung.

In this study we did find detectable concentrations of total IgE in two samples obtained six and eight days after intubation, whereas no IgE had been detected in earlier samples from these patients. We did not measure serum IgE concentrations in these two patients but neither of them came from atopic families. If we assume that their serum albumin concentration was $30 \mathrm{~g} / \mathrm{l}$, serum IgE concentrations of $411 \mathrm{IU} / 1$ and $2272 \mathrm{IU} / 1$ would be required to produce similar IgE/albumin concentrations. This is highly improbable and suggests that the IgE detectable in the BAL samples is not derived from serum. As the concentrations of IgE detected in two samples from the first winter were very close to the lower limit of this method's sensitivity, samples obtained during the second winter were concentrated in an attempt to increase the likelihood of detecting IgE. This has been done in previous studies attempting to identify IgE in BAL samples from adult subjects. ${ }^{23} 25$ Despite concentrating samples between five and 10-fold, no IgE was detected in BAL samples. If IgE is being produced during a primary RSV infection, our failure to detect it in all but two subjects may have a number of explanations. It is possible that even after concentrating samples, concentrations will remain below the limit of detection in most subjects during the first week after developing acute bronchiolitis. Alternatively, it is possible that locally produced IgE is destroyed before being assayed as we did not add a protease inhibitor to these samples. Previous studies assaying total $^{23-25}$ and RSV specific $\operatorname{IgE}^{7-10}$ have not used protease inhibitors and have been able to detect this immunoglobulin, but concentrations measured in this study were close to the limit of detection and any reduction due to the action of proteases may have reduced concentrations below that detectable by this method. The albumin concentrations in BAL samples were significantly higher than noted in previous studies in which BAL fluid was obtained from adult subjects, ${ }^{23} 25$ and this is likely to reflect the intensity of the inflammatory process in these infants.

Messenger RNA for IgE was detected in $50 \%$ of samples obtained from both the upper and lower respiratory tract. The significance of these results is again difficult to interpret. We do not have control samples and as this technique is not quantitative, it is difficult to determine how significant such a result might be. Furthermore, simply detecting the 
presence of mRNA does not necessarily imply that $\mathrm{IgE}$ is being produced as post-transcriptional modification may result in failure to release a product coded for by such a message. However, in the context of previous studies this finding is of interest and needs pursuing.

No mRNA for either interleukin-4 or interferon gamma was detected in four samples in which a positive signal for $T$ cell receptor was obtained. Both play an important part in antibody isotype switching ${ }^{26}$ with interleukin-4 having a central role in directing the antibody response towards a predominantly IgE response and interferon gamma having the opposite effect. It is possible that interleukin-4 is involved in the immune response but went undetected, either because this cytokine's production is maximal before clinical symptoms have occurred or, alternatively, the mRNA for interleukin-4 is degraded by proteases within the bronchial secretions despite the use of 'RNA guard'. It does appear that the influence of this cytokine occurs very early during the activation of $B$ cells and hence its influence may be established well before samples were obtained. Despite the intense inflammation within the airways, mRNA for IgE and $T$ cell receptor could be detected in some samples and hence it would appear unlikely that selective destruction would account for failure to detect mRNA for this cytokine. The failure to detect mRNA for interferon gamma in clinical samples using this method is extremely unusual but is consistent with the results of previous studies that have failed to detect interferon gamma in either the upper ${ }^{2728}$ or lower respiratory tract ${ }^{27}$ secretions from infants with bronchiolitis.

If a RSV specific IgE response plays a part in pathogenesis of acute bronchiolitis, then the relationship between IgE antibodies and symptoms needs to be clarified as it is reported that peak concentrations do not occur until some time after the acute illness. ${ }^{7}$ Furthermore it is difficult to explain why the most severe illness should occur during the first exposure to the virus if IgE plays a central part in modulating the disease. If it does play a central part in the acute illness then it is probable that it acts through activation of mast cells and hence evidence of mast cell actuation was sought. An earlier study showed raised concentrations of histamine in nasal secretions from infants with RSV infection and this was sited as evidence for IgE involvement. ${ }^{7}$ However, it has since been shown that the virus may liberate large amounts of histamine directly from basophils obtained from adults without involving an IgE mediator process. ${ }^{29}$

Tryptase is a mast cell specific product ${ }^{30}$ present in mucosal mast cells and was measured in order to determine whether mast cell degranulation, possibly associated with an IgE response might have a role in this disease. Serum concentrations of tryptase were no higher than controls but this is not altogether surprising. Raised serum tryptase has been described during anaphylactic reactions but concentrations have not been shown to be raised when degranulation is limited to the respiratory tract. ${ }^{30}$ It is of interest that serum concentrations observed in both ventilated and non-ventilated patients were significantly lower than in the control samples but there is no obvious explanation for this. Concentrations in BAL samples were significantly raised compared with controls, suggesting that some mast cell activation occurs in this condition in excess of that attributable to the effects of ventilation. What is unclear is whether these concentrations simply reflect the intensity of the inflammatory response with mast cell degranulation playing only a minor part in the overall picture, or whether the mast cell degranulation is pivotal in the process; it would seem likely that the former is the case. Concentrations in the samples from the infants in this study are lower than those of $1-8 \mathrm{ng} / \mathrm{ml}$ observed in children with stable mild to moderate asthma. ${ }^{31}$ They are also lower than that seen in BAL of non-atopic, non-asthmatic adults $(0.6 \pm 0.4 \mathrm{ng} / \mathrm{ml})$, values in atopic adults with stable asthma $(2 \cdot 0 \pm 1 \cdot 7 \mathrm{ng} / \mathrm{ml})$ are much lower than concentrations observed in BAL from asthmatics after challenge with antigen $(10 \cdot 1 \pm 8 \cdot 2 \mathrm{ng} / \mathrm{m}) .^{32}$ Therefore mast cell degranulation may occur but does not appear to play a major part in the inflammatory process. The two highest tryptase concentrations $(0.85$ and $0.86 \mathrm{ng} / \mathrm{l})$ were in samples obtained shortly after intubation from two separate subjects.

It is of interest that the mRNA results obtained from BAL and nasopharyngeal samples produced the same pattern of results. In an accompanying study, in which cell types and lymphocyte subsets were examined, it was again found that samples from the upper and lower respiratory tract produced very similar results, ${ }^{33}$ suggesting that the inflammatory process can effectively be studied in samples from the upper respiratory tract.

This study has shown that messenger RNA for IgE can be detected in both the upper and lower respiratory tract of infants with RSV positive bronchiolitis. We have also shown detectable concentrations of $\mathrm{IgE}$ in the lower respiratory tract of two patients intubated for RSV bronchiolitis at concentrations suggesting local production. The relationship of these findings to the presence of RSV needs to be defined by further studies. Circulating tryptase concentrations were not raised. Concentrations obtained by bronchial lavage were raised compared with controls but levels were not sufficient to suggest that mast cell degranulation is a major cause of the on going inflammation in this condition. This study suggests that IgE may be produced during acute bronchiolitis as suggested by other workers, but if so, its role in the genesis of acute bronchiolitis remains obscure.

Dr Everard was generously supported by Asthma Nationwide.

$1 \mathrm{Kim}$ HW, Arrobio JO, Brandt CD, et al. Epidemiology of respiratory syncytial virus infection in Washington, DC. I. Importance of the virus in different respiratory tract Importance of the virus in different respiratory tract Am f Epidemiol 1973; 98: 216-25.

2 Martin AJ, Gardner PS, McQuillin J. Epidemiology of respiratory viral infection among paediatric patients over a six-year period in north-east England. Lancet 1978; ii: 1035-8. 
3 Everard $\mathrm{ML}$, Milner $\mathrm{AD}$. The respiratory syncytial virus and its role in acute bronchiolitis. Eur $\mathcal{F}$ Pediatr 1992; 151: 638-51

4 Gardner PS, McQuillin J, Court SDM. Speculation on pathogenesis in death from respiratory syncytial virus infection. $B M \mathcal{F}$ 1970; i: 327-30

5 Brandt CD, Kim KW, Arrobio JO, et al. Epidemiology of respiratory syncytial virus infection in Washington, DC. III. Composite analysis of eleven consecutive yearly epidemics. Am $\mathcal{F}$ Epidemiol 1973; 98: 355-64.

6 Welliver RC, Kaul TN, Ogra PL. The appearance of cellbound IgE in respiratory-tract epithelium after respiratory-syncytial-virus infection. $N$ Engl $f$ Med 1980; 303: tory-syncytial

7 Welliver RC, Wong DT, Sun M, Middleton E, Vaughan RS, Ogra PL. The development of respiratory syncytial RS, Ogra PL. The development of respiratory syncytial
virus-specific IgE and the release of histamine in nasovirus-specific IgE and the release of histamine in nasopharyngeal

8 Welliver RC, Sun M, Rinaldo D, Ogra PL. Respiratory syncytial virus-specific IgE responses following infection: evidence for a predominantly mucosal response. Pediatr Res 1985; 19: 420-4

9 Welliver RC, Sun M, Rinaldo D, Ogra PL. Predictive value of respiratory syncytial virus-specific IgE responses for recurrent wheezing following bronchiolitis. $f$ Pediatr 1986 109: $776-80$.

10 Welliver RC, Sun M, Hildreth SW, Arumugham R, Ogra rL. Respiratory sycytial virus-specific antibody the and G protein Microbiol 1989; 27: 295-9.

11 Toms GL, Scott R. Respiratory syncytial virus and the infant immune response. Arch Dis Child 1987; 62: 544-6.

12 Bui RHD, Molinaro GA, Kettering JD, Heiner DC Imagawa DT, Geme JWS. Virus-specific IgE and IgG4 antibodies in serum of children infected with respiratory syncytial virus. F Pediatr 1987; 110: 87-90.

13 Pullan CR, Hey EN. Wheezing, asthma, and pulmonary dysfunction 10 years after infection with respiratory syncytial virus in infancy. BMF 1982; 284: 1665-9.

14 Carlsen KH, Larsen B, Bjerve $\oslash$, Leegaard J. Acute bronchiolitis: predisposing factors and characterization of infants at risk. Pediatr Pulmonol 1987; 3: 153-60.

15 Sims DG, Gardner PS, Weightman D, Turner MW, Soothill JF. Atopy does not predispose to RSV bronchiolitis or postbronchiolitic wheezing. BMF 1981; 282: 2086-8.

16 Polmar SH, Robinson LD, Minnefor AB. Immunoglobulin $\mathrm{E}$ in bronchiolitis. Pediatrics 1972; 50: 274-84.

17 Belshe RB, Voris LPV, Mufson MA. Parenteral administration of live respiratory syncytial virus vaccine: results of field trial. F Infect Dis 1982; 145: 311-9.

$18 \mathrm{Kim} \mathrm{HW}$, Canchola JG, Brandt CD, et al. Respiratory syncytial virus disease in infants despite prior administration of antigenic inactivated vaccine. Am $\mathcal{f}$ Epidemiol 1968; 89: 422-34.

19 Grigg JM, Arnon S, Silverman M. Fractional processing of sequential bronchoalveolar lavage fluid from intubated babies. Eur Respir f 1992; 5: 727-32.

20 Gough NM. Rapid and quantitative preparation of cytoplasmic RNA from small numbers of cells. Anal Biochem 1998; 173: 93-5.

21 Devalia JL, Campbell AM, Sapsford RJ, et al. Effect of nitrogen dioxide on synthesis of inflammatory cytokines expressed by human bronchial epithelial cells in-vitro. $\mathrm{Am}$ Fespir Cell Mol Biol 1993; 9: 271-8.

22 Walls AF, Bennett AR, McBride HM, Glennie MJ, Holgate ST, Church MK. Production and characterisation of monoclonal antibodies specific for human mast cell monoclonal antibodies specific for human

23 Merrill WW, Naegel GP, Olchowski JJ, Reynolds HY. Immunoglobulin $\mathrm{G}$ subclass proteins in serum and lavage fluid of normal subjects. Am Rev Respir Dis 1985; 131: 584-7.

24 Deuschl H, Johansson SGO. Immunoglobulins in tracheobronchial secretion with special reference to IgE. Clin Exp Immunol 1974; 16: 401-12.

25 Diaz P, Gonzalez C, Galleguillos FR, et al. Leukocytes and mediators in bronchoalveolar lavage during allergeninduced late phase asthmatic reactions. Am Rev Respir Dis 1989; 139: 1383-9.

26 Pene J, Rousset F, Briere F, et al. IgE production by normal human lymphocytes is induced by interleukin-4 and suppressed by interfeons $\gamma$ and $\alpha$ and prostoglandin E2. pressed by interfeons $\gamma$ and $\alpha$ and pros
Proc Natl Acad Sci USA 1988; 85: 6880-4.

27 McIntosh K Interferon in nasal secretions from infants with viral respiratory tract infections. $\mathcal{F}$ Pediatr 1978; 93: 33-6.

28 Isaacs D. Production of interferon in respiratory syncytial virus bronchiolitis. Arch Dis Child 1989; 64: 92-5.

29 Sanchez-Legrand F, Smith TF. Interaction of paramyxoviruses with human basophils and their effect on histamine release. $\mathcal{f}$ Allergy Clin Immunol 1989; 84 538-46.

30 Schwartz LB. Cellular inflammation in asthma: neutra proteases of mast cells. Am Rev Respir Dis 1992; 145: S18-21.

31 Ferguson AC, Whitelaw $M$, Brown $H$. Correlation of bronchial eosinophil and mast cell activation with bronchial hyperresponsiveness in children with asthma. f Allergy Clin Immunol 1992; 90: 609-13.

32 Wenzel SE, Fowler AA, Schwartz LB. Activation of pulmonary mast cells by bronchoalveolar allergen challenge. Am Rev Respir Dis 1988; 137: 1002-8.

33 Everard ML, Swarbrick A, Wrightham M, et al. Analysis of cells obtained by bronchial lavage of infants with respiratory syncitial virus infection. Arch Dis Child 1994; 71. 428-32. 